\title{
COVID-19 and Alzheimer's disease: how one crisis worsens the other
}

\author{
Xiaohuan Xia ${ }^{1,2^{*}}$, Yi Wang ${ }^{1,2}$ and Jialin Zheng ${ }^{1,2,3,4^{*}}$
}

\begin{abstract}
Alzheimer's disease (AD) has emerged as a key comorbidity of coronavirus disease 2019 (COVID-19) caused by severe acute respiratory syndrome coronavirus-2 (SARS-CoV-2). The morbidity and mortality of COVID-19 are elevated in $A D$ due to multiple pathological changes in $A D$ patients such as the excessive expression of viral receptor angiotensin converting enzyme 2 and pro-inflammatory molecules, various AD complications including diabetes, lifestyle alterations in AD, and drug-drug interactions. Meanwhile, COVID-19 has also been reported to cause various neurologic symptoms including cognitive impairment that may ultimately result in $A D$, probably through the invasion of SARS-CoV-2 into the central nervous system, COVID-19-induced inflammation, long-term hospitalization and delirium, and post-COVID-19 syndrome. In addition, the COVID-19 crisis also worsens behavioral symptoms in uninfected AD patients and poses new challenges for AD prevention. In this review, we first introduce the symptoms and pathogenesis of COVID-19 and AD. Next, we provide a comprehensive discussion on the aggravating effects of AD on COVID-19 and the underlying mechanisms from molecular to social levels. We also highlight the influence of COVID-19 on cognitive function, and propose possible routes of viral invasion into the brain and potential mechanisms underlying the COVID-19-induced cognitive impairment. Last, we summarize the negative impacts of COVID-19 pandemic on uninfected AD patients and dementia prevention.
\end{abstract}

Keywords: COVID-19, SARS-CoV-2, Alzheimer's disease, Central nervous system, Inflammation, Cognitive impairment, Angiotensin converting enzyme 2

\section{Background}

Coronavirus disease 2019 (COVID-19), caused by severe acute respiratory syndrome coronavirus-2 (SARS-CoV2 ), is now considered a global public health emergency. SARS-CoV-2 predominantly attacks the human respiratory system and causes fever, colds, throat pains, coughs, dyspnea, and other respiratory symptoms [1]. In severe cases, acute respiratory distress syndrome (ARDS), pneumonia, acute cardiac problems, and multi-system organ failure (MSOF) have been observed [1]. Other atypical respiratory symptoms include headache, dizziness, anosmia, stroke, and deteriorated consciousness or memory

\footnotetext{
*Correspondence: xiaohuan_xia1@163.com; jialinzheng@tongji.edu.cn ${ }^{1}$ Center for Translational Neurodegeneration and Regenerative Therapy, Tenth People's Hospital of Tongji University, Shanghai 200072, China Full list of author information is available at the end of the article
}

[1]. Current evidence has supported that SARS-CoV-2 is capable of targeting and invading the central nervous system (CNS) [2]. In fact, neurological manifestations have occurred in more than one-third of COVID-19 patients with increased infection severity [3].

Alzheimer's disease (AD) is one of the most common CNS comorbidities of COVID-19 [4]. AD is the most prevalent neurodegenerative disorder and the No.1 cause of dementia. In AD patients, brain regions responsible for memory and learning are damaged due to the deposition of amyloid beta $(\mathrm{A} \beta)$ or neurofibrillary tangles (NFT). Patients with moderate and severe $\mathrm{AD}$ are entirely dependent on caregivers. As COVID-19 is highly infectious and its management requires isolation and quarantine, the need of caregivers for AD management conflicts with that of COVID-19 [3, 4]. Therefore, COVID-19 adds

\section{$\triangle B M C$}

(c) The Author(s). 2021 Open Access This article is licensed under a Creative Commons Attribution 4.0 International License, which permits use, sharing, adaptation, distribution and reproduction in any medium or format, as long as you give appropriate credit to the original author(s) and the source, provide a link to the Creative Commons licence, and indicate if changes were made. The images or other third party material in this article are included in the article's Creative Commons licence, unless indicated otherwise in a credit line to the material. If material is not included in the article's Creative Commons licence and your intended use is not permitted by statutory regulation or exceeds the permitted use, you will need to obtain permission directly from the copyright holder. To view a copy of this licence, visit http://creativecommons.org/licenses/by/4.0/ The Creative Commons Public Domain Dedication waiver (http://creativecommons.org/publicdomain/zero/1.0/) applies to the data made available in this article, unless otherwise stated in a credit line to the data. 
extra burden on $\mathrm{AD}$ patients, caregivers, families, society, and the economy.

Identifying common etiological factors would provide new avenues for management and therapeutic strategies against both COVID-19 and AD. In this review, we link COVID-19 and AD by discussing the impacts of one on the other and summarizing the existing problems and potential strategies to improve the management of $\mathrm{AD}$ under the COVID-19 pandemic.

\section{COVID-19}

\section{Epidemiology and symptoms of COVID-19}

COVID-19 has spread worldwide and was declared as a pandemic by the World Health Organization (WHO) in March 2020. By March 24, 2021, a total of 123902242 confirmed cases of COVID-19 worldwide, including 2 727837 deaths, have been recorded by the WHO (https://covid19.who.int/). To date, there have been 85 countries, territories and areas that have had more than 100000 cases each, with the United States having the largest number of confirmed cases.

SARS-CoV-2 belongs to the family Coronaviridae and is an enveloped non-segmented, single-stranded, positivesense RNA virus. SARS-CoV-2 can spread rapidly through various routes including droplets, aerosol, and fomite [5]. Moreover, fecal-oral and fecal-aerosol transmissions are suspected potential routes of SARS-CoV-2, as high viral loads have been detected in patients' feces-related specimens $[6,7]$. The majority of COVID-19 cases develop a lower respiratory tract infection, which leads to the high rate of viral transmission in densely populated areas or hospitals [8]. The median age of COVID-19 patients was reported to be 59 years (range, $15-89$ years), and more than half of them were males [8]. People with low immune function, particularly the elderly and those with renal and hepatic dysfunction, are at a high risk of SARS-CoV-2 infection [8].

SARS-CoV-2 infection causes pneumonia with malaise, dry cough, fever and other symptoms such as lymphopenia, diarrhea, hemoptysis, headache, chills, muscle pain, sore throat, and loss of taste or smell. Generally, SARS-CoV-2 causes milder symptoms and lower case-fatality rate than severe acute respiratory syndrome coronavirus (SARS-CoV) or Middle East respiratory syndrome coronavirus (MERS-CoV), and most patients recover on their own $[9,10]$. However, about $20 \%$ of the patients develop severe symptoms including acute lung injury, ARDS, septic shock, and multiple organ dysfunction syndrome, resulting in rapid death [9]. Besides the pulmonary disease, extrapulmonary manifestations including neurological involvement have received increasing attention.

\section{Pathogenesis of COVID-19}

SARS-CoV-2 enters the host alveoli through the respiratory tract. Inside the alveoli, SARS-CoV-2 infects type II pneumocytes by binding to its functional receptors. Currently, angiotensin converting enzyme 2 (ACE2) has been identified as the main mediator $[11,12]$. ACE2 is a type I integral membrane protein of renin-angiotensin systems and is present on a variety of organs such as the heart, kidneys, and lungs. Spike $(\mathrm{S})$ proteins of both SARS-CoV and SARS-CoV-2 form a trimer harboring a receptor-binding domain (RBD) that interacts with lysine 31 on ACE2 with high affinity [11, 13, 14]. Importantly, SARS-CoV-2 seems to recognize the human ACE2 more efficiently than SARS-CoV, which causes increased infection capacity of SARS-CoV-2 among people [14]. The interaction of the $\mathrm{S}$ protein of SARS-CoV-2 with ACE2 recruits the transmembrane protease serine 2 (TMPRSS2) to cleave the $\mathrm{S}$ protein at the $\mathrm{S} 1 / \mathrm{S} 2$ site (Cterminal segment residues 697 to 716 ), enhancing viral entry $[12,15]$. Other molecules can also mediate SARSCoV-2 infection, since ACE2 knockout could not completely prevent SARS-CoV infection in rodents [16]. CD147 [17] and CD209L (L-SIGN) [18] have been identified as potential receptors for SARS-CoV-2, although more studies are needed to confirm their involvement (Fig. 1).

After being endocytosed into the cytoplasm, SARS$\mathrm{CoV}-2$ utilizes the host cell protein translation machinery to express the coronavirus polymerase complex, which is composed of non-structural proteins (Nsp) including RNA-dependent RNA polymerase (RdRp, Nsp12) and its co-factors (e.g., Nsp7, Nsp8) [19, 20]. RdRp further synthesizes a full-length negative-strand RNA template to make more viral genomic RNA and structural proteins [21-24]. The structural proteins, together with viral RNA, form mature SARS-CoV-2 that is released by exocytosis. This circle leads to uncontrolled viral replication, aggravating the course of COVID-19. Besides the type II alveolar epithelial cells, cardiomyocytes, vascular smooth muscle cells, renal tubular, and intestinal epithelial cells are also predicted to be targets of SARS-CoV-2, as the coexpression of ACE2 and TMPRSS2 has been identified in these cells by single-cell RNA-sequencing analyses [25, 26]. This explains the pathophysiology of acute lung and myocardial injury, and gastrointestinal symptoms reported in COVID-19 cases.

The budding off of SARS-CoV-2 leads to pyroptosis, an inflammatory form of programmed cell death that stimulates alveolar macrophages [27]. The activated macrophages release pro-inflammatory cytokines and chemokines including interleukin-1 (IL-1), interleukin-6 (IL-6), tumor necrosis factor-alpha (TNF- $\alpha$ ), interferon$\gamma$, MCP-1/CCL2, macrophage inflammatory proteins, and $\mathrm{C}-\mathrm{X}-\mathrm{C}$ motif chemokine ligand 10 [28]. These 


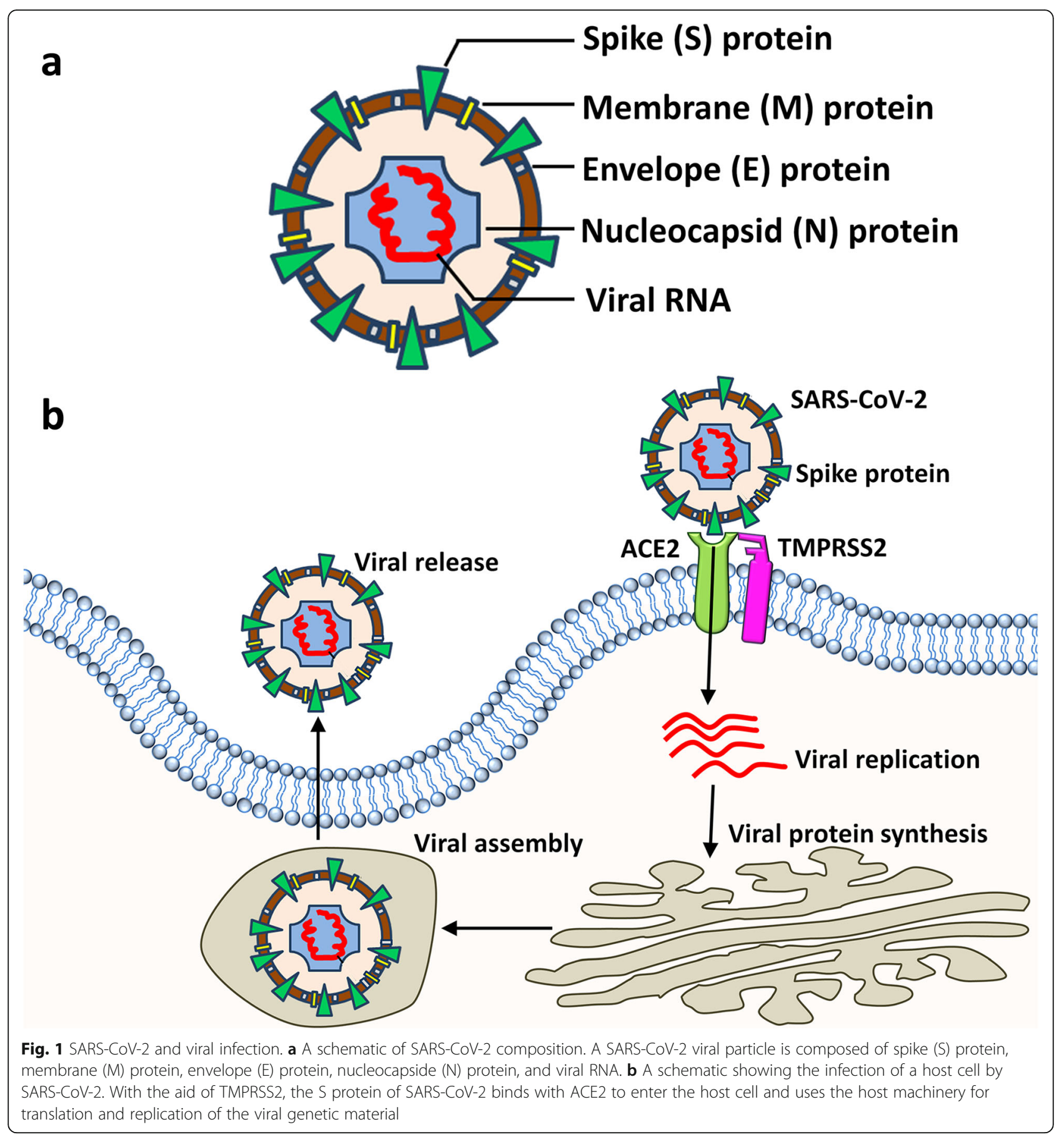

molecules can cause smooth muscle dilation and contraction of blood vessel endothelial cells, negatively influencing the capillary permeability. The rapid increase of cytokines and chemokines causes recruitment of more immune cells (such as $\mathrm{T}$ cells, neutrophils and monocytes) in the blood to the lung tissue [29]. The accumulation of immune cells leads to hyperinflammation and cytokine storm that attack more healthy cells. The leakage of plasma from blood vessels into the interstitial spaces and the destruction of lung parenchyma that reduces surfactant production and alveolus surface tension result in alveolar collapse and alveolar edema. Consequently, gas exchange is impaired and refractory hypoxemia is formed, resulting in ARDS.

Moreover, the excessive vascular cytokines can be taken up by other tissues and trigger the systemic inflammatory response syndrome [30]. Once reaching the CNS, especially the hypothalamus, the excessive IL-1 
and IL-6 may increase the production of prostaglandins, which elevates the core body temperature to initiate fever. The vascular cytokines also induce capillary hyperpermeability, causing the deposition of plasma within various tissues to decrease the total peripheral resistance and blood pressure, resulting in exhausted perfusion [30]. The decreased perfusion further increases the blood urea nitrogen and creatinine in the kidney, leading to acute renal injury [31]. In addition, disseminated intravascular coagulation (DIC) has been reported as a severe complication in some COVID-19 cases [32]. ARDS, severe renal injury and DIC, together with other complications including cardiac dysfunction in COVID19 [1], ultimately lead to MSOF and death.

\section{AD}

AD is the No.1 cause for dementia and is a global public health priority with no effective treatments. The lack of effective treatment is largely due to its unclear pathogenesis. Several hypotheses have been raised to elucidate the mechanism of AD (Fig. 2).

\section{$A \beta$}

The $A \beta$ hypothesis suggests that the accumulation of $A \beta_{40-42}$ produced through sequential cleavage of $\beta$ amyloid precursor protein (APP) by $\beta$ - or $\gamma$-secretase in the brain leads to the formation of senile plaques, which represents the primary pathological process. The $A \beta$ hypothesis is supported by findings from genetics: (1) familial AD mutations of APP and PSEN1/2, transcripts encoding two key components of the $\gamma$-secretase complex, are involved in either $A \beta$ generation or $A \beta$ processing and result in excessive production of $A \beta_{40-42}$ [33]; conversely, an APP missense mutation (A673T) results in a lifelong decrease in APP cleavage by $\beta$ secretase, offering a reduced clinical risk of AD [34]; (2) the epsilon4 allele of apolipoprotein $\mathrm{E}(A p o E)$ is the major genetic risk factor for sporadic $\mathrm{AD}$, highly likely through the effects on $\mathrm{A} \beta$ metabolism [35].

Interestingly, recent studies have indicated that the soluble $A \beta$ oligomers are more toxic than fibrillar $A \beta$ accumulated in dense plaques. The $A \beta$ oligomers purified from $\mathrm{AD}$ brains can inhibit long-term potentiation and cause synaptic dysfunction, dendritic spine damage, and neuronal death of cultured neurons [36]. In addition, $A \beta$ oligomers can induce hyperphosphorylation of tau and the formation of NFT [37]. Therefore, plaques can serve as the "reservoirs" for soluble $A \beta$ oligomers to exert downstream pathological events.

\section{Tau}

NFT that is mainly composed of hyperphosphorylated tau is another hallmark of AD. In parallel with NFT formation, neuronal and synaptic loss occur, so the clinical features and the severity of AD are usually closely correlated with the NFT pathology [38]. Tau hyperphosphorylation and NFT formation usually occur following the formation of senile plaques, suggesting that NFT is a downstream cascade of $A \beta$ accumulation [37]. However, recent studies have indicated that the tau events act independently as tau gene mutations can cause frontotemporal dementia (FTD) without A $\beta$ plaques [39]. This suggests that tau and $A \beta$ may work in parallel to enhance each other's toxicity to drive AD.

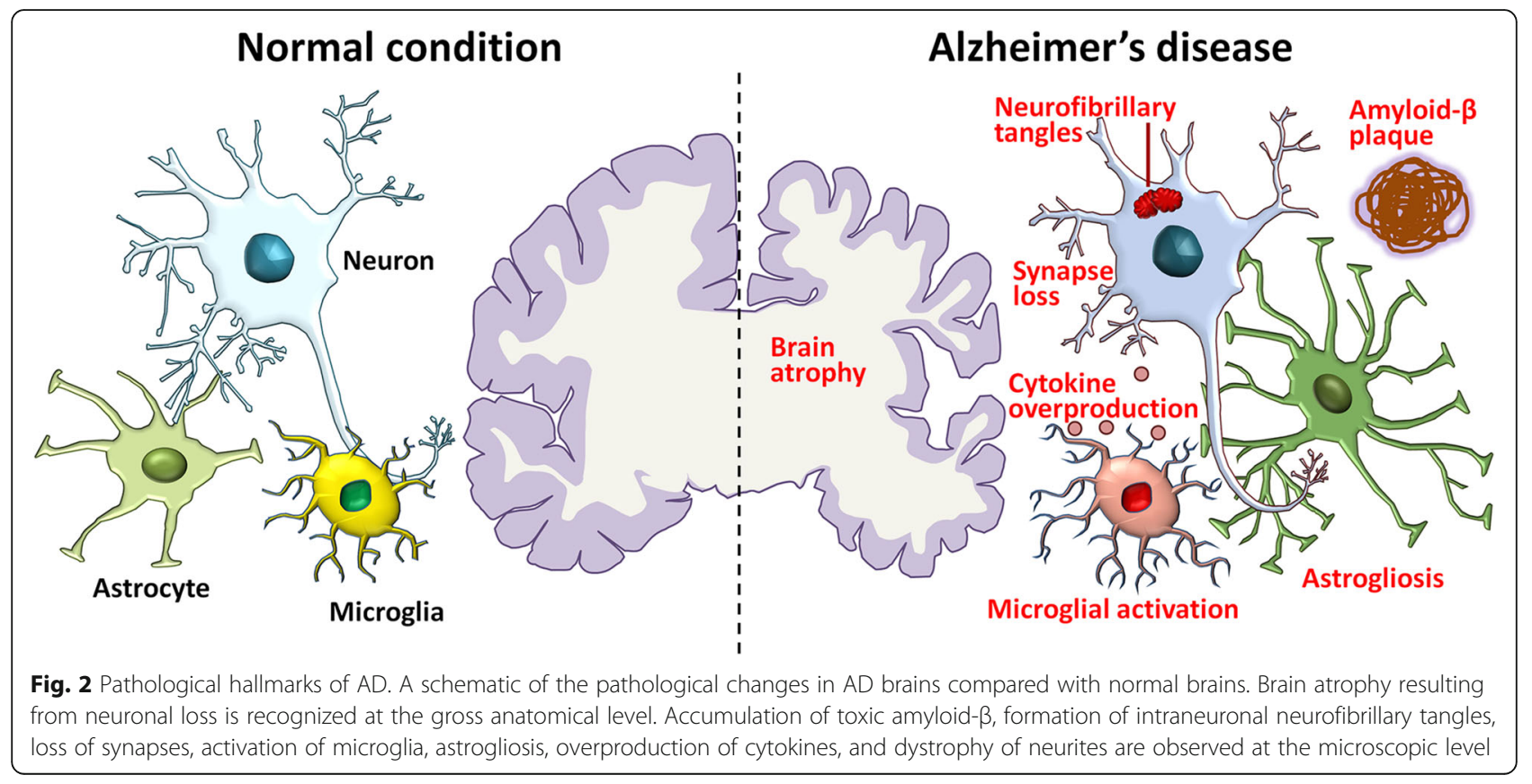


While $A \beta$ and NFT have served as promising hypotheses to explain $A D$, post-mortem examination of these classic pathological hallmarks only explains to a limited degree the levels of $\mathrm{AD}$ and dementia in the population [40]. In addition, all clinical trials with strategies targeting $A \beta$ or NFT have been unsuccessful so far. Therefore, other alternative hypotheses may explain the pathogenic mechanisms of $\mathrm{AD}$ and help design innovative interventional strategies.

\section{Neuroinflammation}

The neuroinflammation hypothesis of $\mathrm{AD}$ was first proposed after the identification of immune elements in senile plaques. Although neuroinflammation has been widely considered to play a key role in the pathophysiology of $\mathrm{AD}$, what remains unclear is whether neuroinflammation acts as the underlying cause, or the consequence, of the disease. Recent evidence has suggested that neuroinflammation contributes to the $\mathrm{AD}$ pathogenesis to an extent no less (if not more) than $A \beta$ or tau, instead of being a passive system activated by accumulated senile plaques or NFT [41]. The strongest supporting evidence is that immune receptors, like triggering receptors expressed on myeloid cells 2 protein [42] and CD33 [43], are closely associated with AD.

Microglia exhibit a heightened activity state in $\mathrm{AD}$, characterized by increased production and release of cytokines and reactive oxygen species [44]. Microglia can recognize and bind to soluble $A \beta$ oligomers and aggregated $\mathrm{A} \beta$ via cell-surface receptors, including multiple CD family members and Toll-like receptors (TLRs) [41]. $\mathrm{A} \beta$ binding activates microglia, leading to the production of proinflammatory molecules. Genetic deletion of CD36, TLR4, or TLR6 in vitro decreases the A $\beta$-induced cytokine production, and terminates cellular $A \beta$ aggregation and the resulting inflammasome activation [45]. Astrogliosis usually occurs following microglial activation, aggravating neuroinflammation [46]. Other cells like blood-derived mononuclear cells, are also a part of the neuroinflammation hypothesis of $\mathrm{AD}$ [47].

\section{Viral infection}

Numerous studies have associated AD with viral pathogens. Comprehensive molecular profiling in a large patient cohort has identified multiple viruses that have an impact on AD-associated biology [48]. Among them, the herpesvirus family including herpes simplex virus (HSV) and human herpesvirus (HHV) is the most studied viral family for AD [48-52]. The hypothesis that considers HSV-1 as a causative factor for the development of AD can be tracked back to 1982 [53]. To date, accumulating results from epidemiological, post-mortem, animal, and cell-culture studies have supported this hypothesis [54].
For example, results from a population-based cohort study showed that the reactivation of HSV seropositivity is highly correlated with incident AD [55]. HSV-induced herpes simplex encephalitis (HSE) causes damage to the hippocampus as well as to the temporal and frontal lobes, same brain areas that are affected in $\mathrm{AD}$, and induces a cognitive phenotype similar to $\mathrm{AD}[56,57]$. HSV-1 DNA has also been shown to specifically colocalize with $\mathrm{AD}$ pathology in the brains of $\mathrm{AD}$ patients [58]. Moreover, cognitive impairment has been observed together with neuroinflammation in infected cortical and brain stem regions in HSE mice [59]. Further studies have demonstrated alterations of $\mathrm{A} \beta$ metabolism, dysregulation of calcium homeostasis, synaptic dysfunction, and apoptosis in cultured human neuronal and glial cells infected with HSV-1 [60]. In addition, anti-HSV drugs have been shown to reduce $A \beta$ and p-tau accumulation in the infected mouse brains [61]. All these findings suggest the strong association of HSV-1 with the pathogenesis of AD. Besides HSV-1, multiscale analysis of three independent Alzheimer's cohorts carried out by Readhead et al. identified increased human herpesvirus $6 \mathrm{~A}$ (HHV-6A) and human herpesvirus 7 in subjects with $\mathrm{AD}$ compared with controls, and demonstrated regulatory relationships linking viral abundance and modulators of $A \beta$ production [48]. Both in vitro and in vivo studies have further shown that HHV-6A infection induces the expression of $A \beta$, the phosphorylation of tau protein, and the activation of microglial cells [48, 51, 52]. The pathological effects of HHV-6A on AD are very likely caused by the suppression of miR-155 and dysregulation of the autophagy/unfolded protein response interplay $[48,51]$. Another animal study revealed that infection of 3xTg-AD mice with mouse hepatitis virus exaggerated tau pathology and accelerated AD progression [62]. These studies provide compelling evidence for the contribution of specific viral species to the development of neuropathology and AD.

In summary, $A \beta$ and NFT are the best-known hypotheses of $\mathrm{AD}$, although they do not entirely elucidate the pathogenic mechanism. Recent evidence has supported for the neuroinflammation hypothesis, though the causality needs to be addressed. Emerging evidence has also implicated viral infection in AD, although future studies are needed to identify the underlying mechanisms for how each specific viral infection leads to AD.

\section{AD increases COVID-19 morbidity and mortality}

Clinicians and scientists have made great efforts in identifying the potential risk factors for COVID-19, and they point out that $\mathrm{AD}$ is strongly linked with the morbidity and mortality of COVID-19. 


\section{AD patients exhibit elevated morbidity and mortality of COVID-19}

Emerging evidence has suggested that AD significantly increases the morbidity of COVID-19. A retrospective study in Spain has suggested cognitive impairment (29.1\%) as one of the most frequent comorbidities in deceased COVID-19 patients [63]. Moreover, AD was the most common diagnosis for cognitive impairment in the confirmed COVID-19 group (9.3\% of all patients) [63]. More importantly, another observational study in Spain reported a higher proportion of COVID-19-infected cases in the AD population (15.1\%) [64]. Given this evidence, AD appears to be an important influential comorbid of COVID-19.

Multiple studies have claimed AD as a key contributor to COVID-19 mortality. Data collected from a tertiary hospital in Spain showed that subjects with cognitive impairment had shorter survival from the onset of symptoms than patients without cognitive impairment [63]. Furthermore, significantly higher death rates were observed in COVID-19 patients with AD (54.5\%), than in patients with FTD $\left(\chi^{2}=4.94, P=0.045\right)$, suggesting that the progression of $\mathrm{AD}$ correlates with the severity of COVID-19 [64]. In addition, a Korean team has evaluated the contribution of various factors, such as age, AD, chronic lung disease, stroke, hypertension, coronary vascular disease, dyslipidemia, chronic kidney disease, diabetes, and history of taking angiotensin II receptor blockers or ACE inhibitors, to the death rate of COVID19 patients in a multicenter retrospective cohort, using multivariate logistic analysis, and found that only age, $\mathrm{AD}$, and chronic lung disease are significant parameters for predicting COVID-19 non-survival $(P<0.05)$ [65]. In addition, data on COVID-19 Case Mortality Rates (CMR) in 93 countries have demonstrated that AD has higher positive correlations with CMR $(r=0.36)$, compared with respiratory diseases including asthma $(r=$ 0.28 ) and chronic obstructive pulmonary disease $(r=$ 0.27) [66]. These findings implicate $\mathrm{AD}$ as an essential population risk factor for COVID-19 mortality.

\section{The potential contributing factors to the AD-mediated elevation of COVID-19 morbidity and mortality Aging}

Aging is the No. 1 risk factor for AD. AD generally (in about $90 \%$ of cases) affects individuals over 65 years and its prevalence doubles every 5 years, generating a timedependent exponential increase [67]. Aging is also a prominent risk factor for severe disease and death from COVID-19 [68, 69]. COVID-19 patients over 59 years are at least 5 times more likely to die after development of symptoms than those below 59 in Wuhan, China [69]. Similarly, the case fatality ratio (CFR) of COVID-19 in the 80 s and above is about 2 -fold higher than the overall
CFR in Italy, the first country affected by the pandemic after China [70]. Aging may induce production of reactive oxygen species, modification of epigenetics, and alterations of gene expression or non-coding RNA expression levels, which contribute to the pathogenesis of both AD and COVID-19 [71, 72].

\section{Lack of self-care and cognitive abilities}

The elevated COVID-19 morbidity in AD patients may be partially due to their distinct living states. AD patients lack the ability to care for themselves and have a reduced awareness of environmental changes. Therefore, a great proportion of $\mathrm{AD}$ patients are living in nursing homes, which, however, were attacked most heavily by the COVID-19 epidemic in many countries. For instance, nursing home residents accounted for $40 \%$ of all deaths in the United States during the first wave of COVID-19 epidemic, although the nursing home population may be less than $1 \%$ of the whole population [73]. Being a respiratory virus, SARS-CoV-2 can propagate rapidly among individuals who live in the same location or work in industries with high degree of interpersonal closeness [73]. The nursing homes have high population density and large household size, providing a perfect environment for SARS-CoV-2 transmission among $\mathrm{AD}$ patients.

The lack of awareness of environmental changes also hinders $\mathrm{AD}$ patients from self-protection. An investigation in Japan reported that the rate of recognition of the COVID-19 pandemic was only $38.2 \%$ in AD patients [74]. Moreover, $74.5 \%$ of the AD patients failed to wear face masks properly by themselves, likely due to the cognitive impairment that further limited their recognition of the pandemic. Consistently, another survey in Japan revealed that only $31 \%$ and $24 \%$ of $\mathrm{AD}$ patients were aware of the COVID-19 epidemic and the reason for wearing a mask, respectively [75]. The lack of awareness on maintaining "social distance" (1.5-2 m) or wearing face masks may increase the infection risk of SARSCoV-2 in $\mathrm{AD}$ patients. AD patients also have difficulties in remembering safeguard procedures, which further increases their risk of infection.

\section{Direct pathologic changes of $A D$}

$A p o E$ is the strongest risk gene for sporadic AD [35], and may be involved in SARS-CoV-2 infection. The $A p o E$ e4 allele has been predicted to increase the risk of severe SARS-CoV-2 infection in the UK Biobank community cohort [76]. Protein products of the ApoE cluster genes may act as SARS-CoV-2 receptors since they have been proved to be receptors for various viruses including hepatitis virus $\mathrm{C}$ and herpesvirus [77]. Moreover, ApoE dysfunction is associated with cardiovascular diseases 
and obesity that increase the vulnerability to COVID-19 $[78,79]$.

AD may facilitate SARS-CoV-2 infection through $\mathrm{Ca}^{2+}$ dysregulation. $A \beta$ oligomers integrate into the plasma membrane and form pores, allowing the passage of $\mathrm{Ca}^{2+}$ [80]. A $\beta$ oligomers also stimulate $N$-methyl- $D$-aspartic acid receptor, $\alpha$-amino-3-hydroxy-5-methyl-4-isoxazolepropionicacid receptor, and L-type voltage-gated calcium channels directly, leading to an increase in intracellular $\mathrm{Ca}^{2+}$ [81]. The abnormally increased intracellular $\mathrm{Ca}^{2+}$ contributes to AD through multiple mechanisms including the formation of NFT, electrophysiological disorder, and neuronal death/degeneration [82]. SARS-CoV and MERS-CoV both utilize $\mathrm{Ca}^{2+}$ for viral infection [83]. Furthermore, various RNA viruses alter $\mathrm{Ca}^{2+}$ homeostasis through the disruption of calcium channels and pumps, resulting in host cell death that benefits viral replication [84]. Thus, despite the lack of sufficient experimental data, it is possible that the $\mathrm{Ca}^{2+}$ dysregulation in $\mathrm{AD}$ brains facilitates the life cycle of viruses, including the spread of viral infection in the COVID-19 epidemic.

Additionally, a genome-wide association study found that the Ace2 gene, but not the Ace1 gene, had higher expression levels in brain tissues from $\mathrm{AD}$ mice than in control samples [85]. In contrast, Ace 2 gene expression levels in the peripheral blood did not differ in healthy versus diseased brain tissues. Similar trends were observed in human brain tissues. Microarray analysis showed that the expression levels of Ace 2 increase with the severity of $\mathrm{AD}[85,86]$. In contrast, $A c e 1$ transcript levels were reduced in brain tissues from $A D$ patients with mild cognitive impairment, compared with healthy donors. The excessive production of ACE2 in AD brains may facilitate the invasion of SARS-CoV-2 into the CNS and accelerate viral transmission. In addition, ACE2 can hydrolyze Ang II to produce Ang-(1-7), and Ang-(1-7) further binds with its receptor Mas to regulate various downstream signaling cascades including the PI3K/Akt/ $\mathrm{CREB} / \mathrm{BDNF} / \mathrm{TrKB}$ pathway $[87,88]$. These findings imply a role of ACE2 in regulating the neurological and mental outcomes of SARS-CoV-2 infection, which needs to be confirmed in future studies [89]. In addition, recent studies have indicated that the reduced activity of the ACE2/Ang(1-7)/Mas axis is largely linked to tau hyperphosphorylation and accumulation of neural internal microtubules and $A \beta$ peptides $[90,91]$. Based on the above evidence, it can be hypothesized that SARSCoV-2 may target ACE2 and repress its expression or activity, causing disturbances in cognitive function and exacerbating cognitive impairment in people with $\mathrm{AD}$, compared with healthy controls and patients with vascular dementia.

Acetylcholine (Ach) is an excitatory neurotransmitter that is essential for memory and learning. Activities of choline acetyltransferase (ChAT), the enzyme responsible for Ach synthesis, are significantly reduced, most severely in the temporal lobe, in AD patients only [92]. Choline uptake and Ach release decrease due to the decline of ChAT activity, causing dramatic presynaptic cholinergic impairment [93]. Thus, major brain functions including memory, learning, waking, and sleep are impaired in AD [93]. The involvement of Ach in COVID-19-driven inflammation has been implied by an in silico study [94], which showed that higher prenatal choline levels in the mother's body can protect the developing brain of the fetus from the adverse effects of SARS-CoV-2 infection. According to these findings, the loss of Ach production in the CNS in AD patients may eliminate an important preventive mechanism against inflammation, contributing to the uncontrolled cytokine storm in COVID-19.

Another key pathological feature of $\mathrm{AD}$ is neuroinflammation. The Alzheimer's brain contains elevated microglial-derived cytokines (e.g., TNF- $\alpha$, IL-1 $\beta$, and IL6 ) and other immune mediators, reflecting a chronic inflammatory microenvironment [95]. Similarly, serum TNF- $\alpha$ and IL- 6 levels have been reported to be significantly higher in AD patients than in healthy donors [96]. As discussed above, COVID-19 induces systemic inflammatory responses and cytokine storm in severe cases [3]. The dramatically elevated cytokine levels in patient serum have been closely correlated with COVID-19 fatality [97]. Plasma proteomics profiling has also identified cytokines/chemokines to be most perturbed in COVID-19 patients and implicated them as early biomarkers to monitor disease severity [72]. Based on this observation, AD and COVID-19 have similar inflammatory signaling. The existing inflammation in $\mathrm{AD}$ patients may accelerate the accumulation of pro-inflammatory cytokines post SARS-CoV-2 infection, exacerbating the immune responses and increasing the mortality of COVID-19.

\section{Comorbidities of $A D$}

Recently, the medical comorbidity of AD has received much attention, since the single-disease framework may weaken the therapeutic effects due to a lack of consideration of multimorbidity. Hypertension (55\%), osteoarthritis (38\%), depression (32\%), diabetes mellitus (26\%), and coronary artery disease (23\%) are five most common comorbidities in AD [98]. Moreover, a comparative study has also identified that the occurrence of morbidities of diabetes mellitus and depression in AD patients is significantly higher than that in controls, suggesting the strong association of $\mathrm{AD}$ with these two illnesses [84]. Diabetes has been reported as a high-risk factor for COVID-19 [99]. In a retrospective study employing multi-center cohorts in China, diabetes has been 
identified as the second most common (19\%) comorbidity in COVID-19 patients [100]. In deceased patients, the percentage of diabetes comorbidity soared to $31 \%$. A whole-population study carried out in England also found that diabetes was associated with significantly increased odds of COVID-19 mortality [101]. Diabetes has been proposed to increase the in-hospital death of COVID-19 patients via cardiovascular events, thromboembolism, and DIC [102]. In addition, hypertension and coronary heart disease are common comorbidities of both AD and COVID-19 [98, 100]. However, whether AD could increase the risk of hypertension and coronary heart disease remains controversial, since physicians tended to underdiagnose other illnesses in $\mathrm{AD}$ patients due to the inability of the patients to describe or remember specific complaints and to cooperate with extensive diagnostic tests [103]. Overall, these clinical studies reveal that $\mathrm{AD}$ comorbidities, especially diabetes, are associated with poor outcomes of COVID-19.

\section{Drug-drug interactions}

Currently, cholinesterase inhibitors (ChEIs) (e.g., donepezil, rivastigmine and galantamine) are widely used for AD treatment [104]. The ChEIs can be affected by substracts, inhibitors or inducers of the cytochrome $\mathrm{P} 450$ (CYP450) enzymes (e.g., CYP2D6, CYP3A4) [105]. Potential drugs for COVID-19 such as chloroquine (CQ) and hydroxychloroquine (HCQ) can be metabolized by CYP2D6 and CYP3A4, which may lead to significant alterations of the pharmacological effects of ChEIs [106]. A similar situation may be observed when azithromycin, another potential drug for COVID-19, is used with AD treatment. Besides, the anti-viral protease inhibitor lopinavir/ritonavir inhibits CYP3A and CYP2D6, activates CYP1A2, CYP2B6, CYP2C19, CYP2C9 and glucuronyl transferase enzymes, and suppresses drug transporters like glycoprotein [107]. Lopinavir/ritonavir may increase the plasma concentrations of ChEIs, resulting in adverse reactions or toxicity risk [106]. Thus, cardiac adverse effects (such as bradycardia, heart block, and QT interval prolongation) may appear in relation to both ChEIs and $\mathrm{CQ} / \mathrm{HCQ}$ or azithromycin, which ultimately elevates the death rate of COVID-19 [106].

\section{Nutritional disorders}

Malnutrition has been identified with high prevalence in AD patients of different severity. A study carried out in Italy reported that over $95 \%$ of $\mathrm{AD}$ patients were in a malnourished condition or were at high risk of malnutrition [108]. In a cross-sectional study, over one-fourth of the COVID-19 patients were at risk of malnutrition and more than half of the COVID-19 patients were in a state of malnutrition in China [109]. Malnutrition is associated with the length of hospital stay and the in-hospital mortality [110, 111]. For instance, the incidence of diabetes and other comorbidities is also significantly altered in COVID-19 patients with risk of malnutrition or in malnutrition [109]. Therefore, malnutrition caused by AD may negatively affect the prognosis of COVID-19.

In summary, growing evidence has implicated $\mathrm{AD}$ in the pathogenesis of COVID-19. Individuals with $\mathrm{AD}$ present pathological abnormalities from molecular to system levels, together with lifestyle alterations. All these changes would in turn dramatically increase the morbidity and mortality of COVID-19 via increasing the infection risk, facilitating viral infection, worsening patient conditions, and accelerating patient death. Therefore, more intensive care is urgently needed to improve the situation of AD patients in the COVID-19 crisis and specialized/personalized therapeutic strategies are required in the treatment of COVID-19 patients with AD.

\section{COVID-19 may promote the initiation and progression of $A D$}

It is increasingly evident that COVID-19 may lead to neurological symptoms [3], which include, but are not limited to, dizziness, headache, impaired consciousness, and seizure. Besides acute neurological issues, long-term neurological consequences of COVID-19 including AD have emerged as an area of concern.

\section{COVID-19 contributes to cognitive impairment}

The negative effects of COVID-19 on cognitive function have been demonstrated by studies worldwide. An observational study in China demonstrated that $14.8 \%$ of COVID-19 patients suffered from impaired consciousness [3]. Similarly, a relevant proportion of patients after critical SARS-CoV-2 infections show memory and executive function deficits in Europe [112, 113]. In an observational study, $65 \%$ of patients were noted to have confusion according to the Confusion Assessment Method for the intensive care unit (ICU) [113]. At discharge, 15 of 45 (33\%) patients still had cognitive and motor deficits, including inattention, disorientation, or poorly organized movements in response to command. This is consistent with existing data that long-term cognitive impairment is commonly present in ARDS survivors at discharge [114]. Therefore, cognitive deficits commonly occur in COVID-19 patients, who may develop $\mathrm{AD}$ as a long-term consequence.

\section{Potential routes for SARS-CoV-2 invasion into the CNS}

Multiple studies have independently demonstrated CNS infection of SARS-CoV-2 in postmortem brain tissues of COVID-19 patients, animal models, and cultured cells $[115,116]$. SARS-CoV-2 may enter the CNS either through the indirect hematogenous route or the direct neural route (Fig. 3) [117]. Viral RNA has been detected 


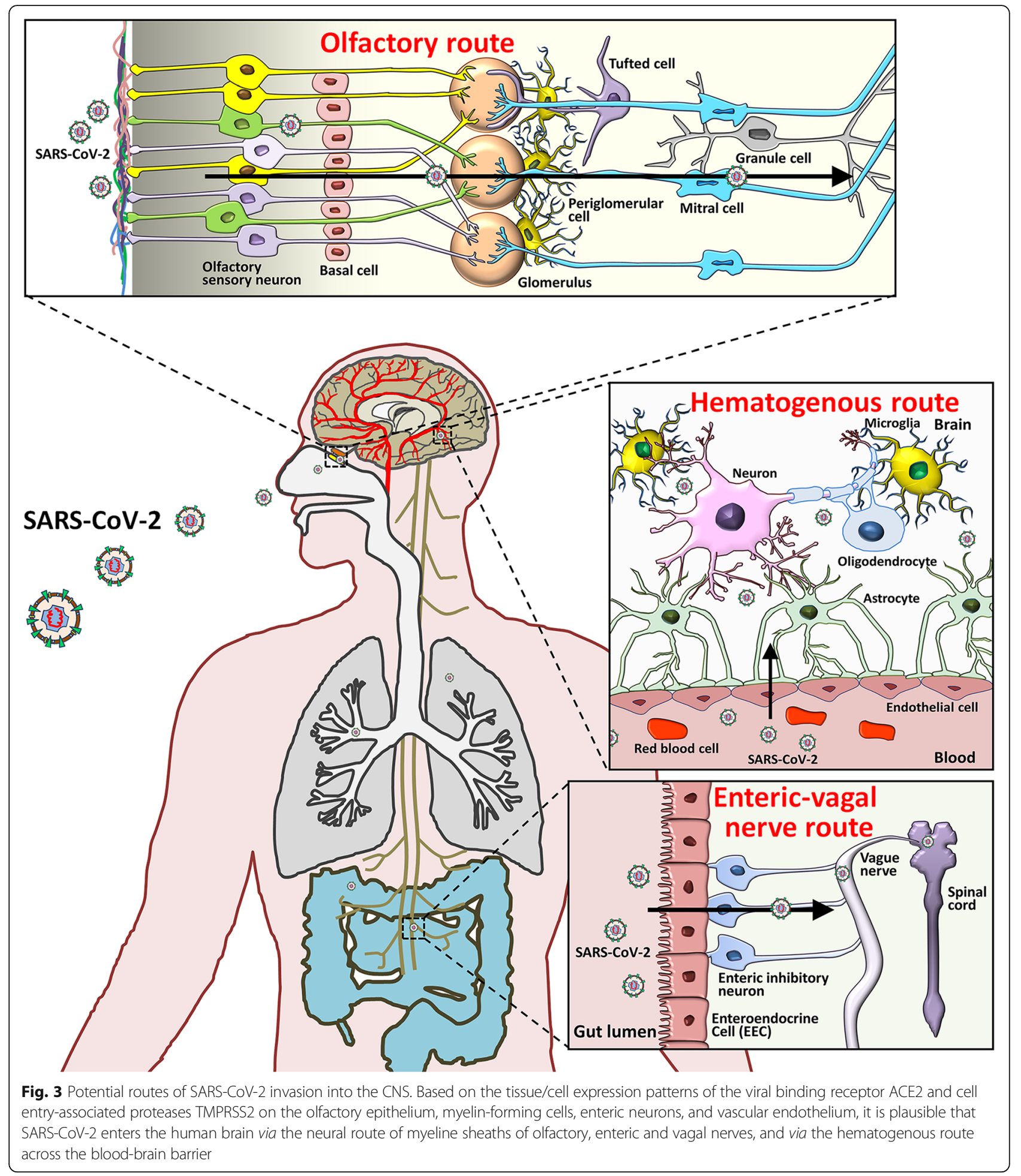

in the peripheral blood specimens collected from COVID-19 patients on the first 2 to 3 days after the onset of symptoms [118]. The presence of SARS-CoV-2 in blood allows it to pass into the cerebral circulation, where the slow blood flow may facilitate the interaction of SARS-CoV-2 S protein with ACE2 expressed on the capillary endothelium [117]. Subsequent budding of viral particles from the capillary endothelium leads to endothelial lining damage, which may further aid viral access to the brain [117]. This premise has been confirmed in an advanced 3D microfluidic model of the human blood-brain barrier [119]. In this model, the SARS-CoV- 
2 protein triggers a pro-inflammatory response on brain endothelial cells and promotes loss of barrier integrity, which can assist the invasion of SARS-CoV-2 to the brain. In vitro studies have further indicated that, once within the neuronal tissues, SARS-CoV-2 interacts with ACE2 and infects neurons [115, 120]. Treatment with ACE2 antibodies or cerebrospinal fluid from a COVID19 patient significantly inhibited the viral infection of neurons [115]. Importantly, before the occurrence of the proposed neuronal damage, endothelial ruptures in cerebral capillaries and bleeding within cerebral tissue may lead to fatal consequences in patients with SARS-CoV-2 infections [117].

The hematogenous route can explain cerebrovascular symptoms, but falls short of explaining neurological symtpoms like olfactory or gustatory dysfunctions that, in some COVID-19 cases, occur even before repiratory symptoms [121]. Previous studies have demonstrated the invasion of SARS-CoV to the brain of a transgenic mouse expressing human ACE2 via nose close to the olfactory epithelium [122]. Similarly, SARS-CoV-2 has also been reported to infect the brain tissues of transgenic mice with human ACE2 expression by intranasal administration, supporting the hypothesized olfactory route for SARS-CoV-2 entry to the human brain [123]. The findings that ACE2 and TMPRSS2 are expressed in olfactory sensory neurons, olfactory epithelial supporting and stem cells [124], and CNS cells [120], further support neural invasion by SARS$\mathrm{CoV}-2$ through the olfactory route. SARS-CoV-2 also appears to be able to enter the CNS via vagus and enteric nerves as ACE2 and TMPRSS2 expression has been confirmed in enteric neurons and glia [125]. In human intestinal organoids, SARS-CoV-2 can infect and replicate in enterocytes [126]. Therefore, the spread of SARS-CoV-2 in the CNS through the vagus nerve that synapses to enteric neurons seems to be another invasion mechanism. To summarize, SARS-CoV-2 may invade the CNS through hematogenous and neural (olfactory and entericvagal) routes.

\section{Potential mechanisms of COVID-19-mediated cognitive impairment}

COVID-19 affects cognitive function in complex ways. First, studies have suggested that viral infection per se increases the risk of cognitive impairment directly or indirectly [117]. Second, COVID-19 management poses greater risk of cognitive impairment on individuals due to the required isolation. In this section we discuss the potential mechanims through which the COVID-19 pandemic induces cognitive impairment.

\section{Viral infection}

SARS-CoV-2 presents neurotropism and is likely to be able to cause cognitive impairment directly in a similar way to SARS-CoV [117]. However, at present, there is no solid evidence showing direct induction of cognitive dysfunction by SARS-CoV-2 infection. Thus, scientists speculate that the virus probably exerts its effects on cognition via indirect pathways. First, the virus may affect cognition by attacking the cerebral vascular system. Varga et al. have reported that SARS-CoV-2 produces endothelitis, which is a root cause for several pathological conditions like cerebral ischemia [127]. Large-vessel stroke is another cerebral vascular disease that may be directly attributed to viral infection in people, especially young people, infected with SARSCoV-2 [128]. A case report has also demonstrated the occurrence of small asymptomatic ischemic strokes in COVID-19 patients hospitalized in an ICU in France [113]. These results indicate a correlation between SARS-CoV-2 infection and impaired brain function; however, the causality remains to be determined.

Previous studies on other human coronaviruses may shed light on this question. Animal studies on human coronavirus OC43 have revealed that the hippocampus (especially CA1 and CA3 regions), which controls memory and cognition, seems particularly vulnerable to coronavirus infection [129, 130]. This hippocampal vulnerability is highly likely to cause negative effects on learning and memory. However, more studies are required to address the questions of whether human coronavirus infection leads to the similar hippocampal-related degeneration as in $\mathrm{AD}$ and accelerates disease onset in previously unaffected individuals.

\section{Inflammation}

A great proportion of COVID-19 patients show a severe innate immune response and sustained rise of systemic cytokine levels. The systemic inflammation has been demonstrated to impact cognitive function and promote progression of neurodegenerative diseases [41]. For example, human cognitive performance has been inversely correlated with chronic peripheral elevation of IL-6 [131]. Similarly, increased IL-1 $\beta$ in rodent brains results in impairment of long-term potentiation and cognitive performance, together with elevated $A \beta$ and NFT production [132]. Furthermore, knockout or blockade of proinflammatory cytokines such as IL-6 and IL-1 improves reference and spatial memory and causes better cognitive performance as ascertained by multiple memory and learning behavioral tests $[133,134]$. In addition, COVID-19 may induce the activation of the NOD-, LRR- and pyrin domain-containing protein 3 (NLRP3) inflammasome, which plays a key role in the development of ARDS [135]. After being activated, the NLRP3 inflammasome exerts adverse effects on the normal phagocytic function of microglia, leading to the failure of $A \beta$ clearence in the brain [136]. Therefore, COVID- 
19-induced inflammation, especially the cytokine storm, may directly lead to cognitive dysfunction and neurodegeneration, and COVID-19 survivors may experience $\mathrm{AD}$ in the following years.

\section{Potential APP metabolism dysfunction}

Surprisingly, several recent multi-omic analyses of samples from COVID-19 patients have revealed a potential relationship between COVID-19 and APP metabolism. For example, RNA-seq analysis has demonstrated a significant increase of $A P P$ transcript in the blood samples from COVID-19-positive patients, compared with COVID-19-negative ones in the United States [137]. Furthermore, a single-cell RNA-seq study carried out by Yang and colleagues has identified $A P P$ as one of the most up-regulated genes in oligodendrocytes isolated from the post-mortem brain tissues of COVID-19 patients [138]. However, it is worth noting that the dysregulation of APP metabolism-related genes in COVID-19 patients is not constantly observed among multi-omic studies. Multi-transcriptome sequencing in the red blood cell-depleted whole blood failed to identify any difference in the expression levels of APP and PSEN1/2 between COVID-19 patients and uninfected donors in China [139]. Similarly, no siginificant difference was observed in the levels of transcripts of APP and PSEN1/2 between SARS-CoV-2-infected and uninfected human pluripotent stem cell (hPSC)-derived brain organoids [140]. Thus, whether or not COVID-19 influences APP metabolism remains an open question that needs to be addressed in the future.

\section{Long-term hospitalization and delirium}

It has been reported that neurological issues have occurred in up to $20 \%$ of COVID-19 patients who require ICU admission [3]. Multiple symptoms, such as anxiety, depression, prolonged pain, impaired cognitive and physical function that are known as post-intensive care syndrome, commonly occur in ICU patients. In ARDS that is not caused by COVID-19, up to $70 \%-100 \%$ of individuals show cognitive problems such as impaired executive function, short-term memory deficit and anxiety at discharge [114]. At 1 or 2 years post-hospital discharge, the proportions of ARDS survivors with cognitive impairment remain at around 50\% [114]. Around $20 \%$ of ARDS survivors suffer from cognitive deficits like impaired executive function, short-term memory deficit, and anxiety at 5 years [114]. More importantly, animal studies have demonstrated that isolation or restraint stress that mimicks long-term hospitalization and delirium, significantly promotes amyloid plaque formation and tau phosphorylation in AD mice [141, 142]. These observations indicate that patients who require longterm hospitalization or recover from COVID-19 after leaving ICU are potentially at higher risk of long-term residual neurocognitive conditions, which may play a significant role in the development of $\mathrm{AD}$ after critical COVID-19.

\section{Post-COVID-19 syndrome}

COVID-19 may cause long-term adverse effects, similar to SARS [143]. After an acute SARS episode, many patients develop chronic fatigue syndrome/myalgic encephalomyelitis, sickness syndrome manifestations (malaise, anorexia, fatigue, and myalgia), endocrinopathy, long-term psychiatric conditions such as post-traumatic stress disorder (PTSD), and other syndromes. These are collectively called the "post-SARS syndrome" [143-145]. It is hypothesized that COVID-19 survivors may experience similar long-term adverse effects as those with post-SARS syndrome [143]. To date, post-COVID-19 paediatric inflammatory syndrome, Guillain-Barré syndrome, depression, and PTSD have been reported by various independent studies [146]. Unfortunately, apart from the chronic inflammation discussed above, other symptoms that are observed in post-COVID-19 syndrome may also be linked with AD. For instance, Guillain-Barré syndrome cases present with increased serum levels of transforming growth factor- $\beta 1$ (TGF- $\beta 1$ ) [147]. An abnormal increase of TGF- $\beta 1$ in the brains of AD patients has also been detected, which may be associated with neuroinflammation and neuronal apoptosis [148]. Moreover, the TGF- $\beta 1$-overexpressing mice exhibit AD-like cerebrovascular pathology, further validating the involvement of TGF- $\beta 1$ in the pathogenesis of AD [148]. These observations imply the involvement of post-COVID-19 Guillain-Barré syndrome in AD, which needs to be studied further in detail. Besides the Guillain-Barré syndrome, psychiatric conditions after COVID-19 may also contribute to the development of AD. Animal studies have shown that PTSD-like induction accelerates the accumulation of $\mathrm{A} \beta$ through disrupting the corticotropin-releasing factor signaling, suggesting that the PTSD-like trauma can drive AD pathogenesis [149]. Similarly, depression-like stress also improves the progression of $\mathrm{AD}$ in rodents, most likely through elevating the levels of $A \beta$ and phosphorylated tau $[141,142,150]$.

Besides the aformentioned mechanisms, COVID-19 may also contribute to cognitive impairment in other ways such as cerebral ischemic damage, since vascular remodeling in infected regions has been observed in SARS-CoV-2-infected mouse brains independent of vascular infection [88]. Therefore, various studies have implied that COVID-19 can induce cognitive impairment, which may ultimately lead to the development of $\mathrm{AD}$. The potential mechanisms include, but are not restricted to, the invasion of SARS-CoV-2 into the CNS, COVID- 
19-induced inflammation, long-term hospitalization and delirium, and post-COVID-19 syndrome. However, it will remain unknow whether $\mathrm{AD}$ is a long-term complication of COVID-19 untill solid evidence is obtained. More comprehensive investigations are needed to understand the contribution of COVID-19 to AD.

\section{Future work for clarifying the relationship between COVID-19 and AD}

Although multiple studies have reported cognitive impairment in COVID-19 patients that suggests the potential roles of COVID-19 in AD development, there is still a lack of adequate evidence to support this relationship. The following studies may be necessary for clarifying this question.

First, short-term laboratory-based studies can be carried out immediately. For example, by using various $\mathrm{AD}$ animal models, the key AD pathological consequenes of SARS-CoV-2 infection can be examined, including cognitive functions, accumulation rate of amyloid plaque and NFT, and activation of immune cells in the brain, based on which a clue can be made on whether COVID19 increases the risk of $\mathrm{AD}$ in populations with highpenetrant mutations of $\mathrm{AD}$ risk gene variants and whether it expedites the disease progression in $\mathrm{AD}$ patients. More excitingly, the hPSC-derived brain organoid models provide an excellent platform to mimick the situation of SARS-CoV-2 infection in the brains of AD patients [151]. By utilizing AD brain organoids, the effects of SARS-CoV-2 infection on the expression of AD risk genes and the degeneration of neurons can be determined, providing valuable information for the association of COVID-19 with AD.

Second, the COVID-19 patient samples including blood samples collected during hospitalization and postmortem tissues provide a valuable source for research. To date, there have been very few studies examining the AD-related pathological changes in post-mortem tissues from COVID-19 patients, especially brain tissues. Furthermore, the sample sizes in these studies are very limited. These limitations have hindered our understanding of the potential causal effect of COVID-19 on AD. Therefore, studies with larger sample sizes and more specific classification (e.g., brain tissues from patients with both AD and COVID-19) are needed.

Third, it is essential to establish a long-term follow-up system for COVID-19 patients. With the huge number of confirmed cases of COVID-19, it is possible to build up large cohorts of COVID-19 patients, especially the aged patients. After long-term follow-up, many important retrospective studies could be carried out to demonstrate whether COVID-19 survivors have increased incidence of AD.

\section{The COVID-19 crisis negatively affects uninfected AD patients}

The majority of $\mathrm{AD}$ patients are people living with dementia (PLwD) who rely on caregivers. Preventive strategies to combat COVID-19, such as isolation or quarantine, increase the burden of uninfected AD patients who need routine care and support. In this section, we discuss the effects of COVID-19 on uninfected $\mathrm{AD}$ patients or populations with $\mathrm{AD}$ risk.

\section{COVID-19 restrictions cause worsening of behavioral symptoms in $A D$ patients}

The COVID-19 epidemic has caused multiple social problems and concerns in AD patients without the viral infection. It has become obvious that the COVID-19driven social isolation and quarantine have various adverse effects. People suffer from loneliness, depression and anxiety, and this situation is even worse for AD patients. Quarantine induces a rapid increase of behavioral and psychological symptoms in approximately $60 \%$ of patients with dementia including AD, FTD, dementia with Lewy bodies, and vascular dementia. In particular, $\mathrm{AD}$ patients have higher risk of anxiety than other types of dementia [152]. These behavioral problems are not restricted to people living in their own houses but also reported in $\mathrm{AD}$ patients who live in retirement homes, which are forced to physically isolate their residents.

Moreover, worsened depression and anxiety symptoms associated with the restrictions of COVID-19 have also been observed, similar to the situation of quarantine [153]. A survey in Argentina has reported worsening of behavioral symptoms in elderly subjects with dementia living in the community. About $60 \%$ of subjects with dementia during the epidemic displayed new onset of behavioral symptoms or exacerbation of pre-existing behavioral symptoms. Symptoms of anxiety, depression, and sleep disorders accounted for about 33\%, 13\% and $15 \%$ of the subjects, respectively [154]. The "stay-athome" and visitation restrictions under COVID-19 save lives, at a cost of the mental health of PLwD and caregivers, as "non-essential" activities like psychosocial interventions are cut due to the safety concerns [155]. Therefore, negative consequences such as loneliness, agitation, depression, and caregiver burden may arise, and what to make things worse is that these people were left there to handle long-term mental health problems by themselves. Therefore, online services are urgently needed to continue routine interventions for PLwD.

\section{The COVID-19 pandemic has adverse effects on AD prevention}

The isolation or contact restriction in the COVID-19 pandemic not only causes problems for AD patients, but also leads to adverse consequences for $\mathrm{AD}$ prevention. 
Physical activity (PA) has been identified as a key factor in preventing $\mathrm{AD}$ through improving cerebral perfusion, facilitating neurogenesis and synaptogenesis, reducing neuronal loss, preserving brain volume in regions vulnerable to $\mathrm{AD}$, and inhibiting $\mathrm{A} \beta$ accumulation and tau phosphorylation [156]. PA also significantly reduces the risk of myocardial infarction, stroke, and diabetes, which, in turn, diminishes AD morbidity [156]. Physical inactivity is assumed to account for one-third of the global prevalence of AD [157]. However, COVID-19 restrictions have curtailed PA globally, especially in the elderly [158]. A crosssectional online survey suggests that there has been a 26.5\% decrease of PA level in the older community in Japan. Similarly, a global decrease (mean $27.3 \%$ within 30 days following the declaration of a pandemic) of daily steps was reported in a descriptive study. These alarming results demonstrate that under the circumstances of the COVID-19 pandemic, new preventive approaches are needed that account for the suspected long-term lifestyle changes [158].

\section{Conclusions}

SARS-CoV-2 has caused a global pandemic of COVID-19. Apart from attacking the respiratory system, current evidence suggests that SARS-CoV-2 is able to invade the CNS through hematogenous and neural routes and cause neurological problems that include cognitive impairment via viral infection, neuroinflammation, APP metabolism dysfunction, long-term hospitalization and delirium, post-COVID-19 syndrome, and other possible mechanisms [1]. On the other hand, AD has been indicated as one of the most common CNS comorbidities of COVID19 , imposing a greater burden on patients, society, and the economy. AD significantly increases COVID-19 morbidity and mortality due to aging, the AD-induced direct and indirect pathologic changes, drug-drug interactions, nutritional disorders, and the lack of self-care and cognitive abilities of AD patients. Moreover, the isolation or contact restriction in the COVID-19 pandemic also negatively affects uninfected $\mathrm{AD}$ patients and hinders $\mathrm{AD}$ prevention. Hence, all these findings suggest the importance to understand the underlying neurobiology of COVID-19, which needs to be clarified in future work.

Future studies on the relationship between COVID-19 and $\mathrm{AD}$ can be designed in the following aspects: (1) to identify the mechanisms of how SARS-CoV-2 invades the CNS and infects CNS cells; (2) to extensively investigate the reasons for increased COVID-19 mortality among $\mathrm{AD}$ patients and design corresponding therapeutic strategies; (3) to demonstrate the effects of COVID-19 on the AD-relevant pathological and behavioral changes using animal models and patient samples; (4) to establish long-term follow-up cohorts for analyzing the correlation between COVID-19 and AD; and (5) to develop new interventions that enable people to access required care under the likely long-lasting effects of COVID-19.

\begin{abstract}
Abbreviations
$A B$ : Amyloid-beta; ACE2: Angiotensin converting enzyme 2; Ach: Acetylcholine; AD: Alzheimer's disease; ApoE: Apolipoprotein E; APP: Amyloid precursor protein; ARDS: Acute respiratory distress syndrome; ChAT: Choline acetyltransferase; ChEl: Cholinesterase inhibitor; CMR: Case mortality rates; CNS: Central nervous system; COVID-19: Coronavirus disease 2019; DIC: Disseminated intravascular coagulation; FTD: Frontotemporal dementia; HHV-6A: Human herpesvirus 6A; hPSC: Human pluripotent stem cell; ICU: Intensive care unit; IL-1: Interleukin-1; IL-6: Interleukin-6; MERSCoV: Middle East respiratory syndrome coronavirus; MSOF: Multi-system organ failure; NFT: Neurofibrillary tangle; NLRP3: NOD-, LRR- and pyrin domain-containing protein 3; Nsp: Non-structural proteins; PA: Physical activity; PLwD: People living with dementia; PTSD: Post-traumatic stress disorder; RBD: Receptor binding domain; RdRp: RNA-dependent RNA polymerase; SARS-CoV: Severe acute respiratory syndrome coronavirus; SARSCoV-2: Severe acute respiratory syndrome coronavirus-2; S protein: Spike protein; TGF- $\beta 1$ : Transforming growth factor- $\beta 1$; TMPRSS2: Transmembrane protease serine 2; TNF-a: Tumor necrosis factor-alpha; WHO: World health Organization
\end{abstract}

\section{Acknowledgements}

We thank Dr. Matthew Mitchell from Philosophy and Religious Studies, Allegheny College, and Ms. Jie Zhu, Dr. Xinrui Qi and Ms. Yanyan Zhang from Center for Translational Neurodegeneration and Regenerative Therapy, Tenth People's Hospital of Tongji University for proofreading the manuscript.

\section{Authors' contributions}

J.Z., X.X. conceived the manuscript. X.X., Y.W. collected references. X.X., Y.W. wrote the manuscript. X.X. prepared illustrations. The authors read and approved the final manuscript.

\section{Funding}

This review was supported in part by research grants from the National Natural Science Foundation of China (No. 91949204 and No. 81830037 to J.Z., No. 81971145 and No. 81901333 to X.X., No. 81801063 to Y.W.), Shanghai Sailing Program (No. 19 YF1451700 to X.X.), Clinical Research Fund from Shanghai Municipal Health Commission (No. 20204 Y0031 to Y.W.), Shanghai Blue Cross Brain Hospital Co., Ltd., and Shanghai Tongji University Education Development Foundation (No. 000000381/2018108 to J.Z.).

\section{Availability of data and materials}

Not applicable.

\section{Declarations}

Ethics approval and consent to participate Not applicable.

\section{Consent for publication}

The authors approved the final manuscript.

\section{Competing interests}

The authors declare no conflict of interests regarding the publication of this paper.

\section{Author details}

${ }^{1}$ Center for Translational Neurodegeneration and Regenerative Therapy, Tenth People's Hospital of Tongji University, Shanghai 200072, China.

${ }^{2}$ Translational Research Institute of Brain and Brain-Like Intelligence, Shanghai Fourth People's Hospital Affiliated to Tongji University School of Medicine, Shanghai 200434, China. ${ }^{3}$ Collaborative Innovation Center for Brain Science, Tongji University, Shanghai 200092, China. ${ }^{4}$ Department of Pharmacology and Experimental Neuroscience, University of Nebraska Medical Center, Omaha, NE 68198-5930, USA. 
Received: 17 December 2020 Accepted: 5 April 2021 Published online: 30 April 2021

\section{References}

1. Guan WJ, Ni ZY, Hu Y, Liang WH, Ou CQ, He JX, et al. Clinical characteristics of coronavirus disease 2019 in China. N Engl J Med. 2020;382(18):1708-20.

2. Desforges M, Le Coupanec A, Dubeau P, Bourgouin A, Lajoie L, Dube M, et al. Human coronaviruses and other respiratory viruses: underestimated opportunistic pathogens of the central nervous system? Viruses. 2019;12(1): 14

3. Mao $L$, Jin $H$, Wang M, Hu Y, Chen $S$, He Q, et al. Neurologic manifestations of hospitalized patients with coronavirus disease 2019 in Wuhan, China. JAMA Neurol. 2020;77(6):683-90.

4. Fotuhi M, Mian A, Meysami S, Raji CA. Neurobiology of COVID-19. J Alzheimers Dis. 2020;76(1):3-19.

5. Wiersinga WJ, Rhodes A, Cheng AC, Peacock SJ, Prescott HC. Pathophysiology, transmission, diagnosis, and treatment of coronavirus disease 2019 (COVID-19): a review. JAMA. 2020;324(8):782-93.

6. Feng B, Xu K, Gu S, Zheng S, Zou Q, Xu Y, et al. Multi-route transmission potential of SARS-CoV-2 in healthcare facilities. J Hazard Mater. 2021:402: 123771

7. Cuicchi D, Lazzarotto T, Poggioli G. Fecal-oral transmission of SARS-CoV-2: review of laboratory-confirmed virus in gastrointestinal system. Int J Color Dis. 2021:36(3):437-44.

8. Li Q, Guan X, Wu P, Wang X, Zhou L, Tong Y, et al. Early transmission dynamics in Wuhan, China, of novel coronavirus-infected pneumonia. N Engl J Med. 2020;382(13):1199-207.

9. Chen Y, Liu Q, Guo D. Emerging coronaviruses: genome structure, replication, and pathogenesis. J Med Virol. 2020;92(4):418-23.

10. Gerges Harb J, Noureldine HA, Chedid G, Eldine MN, Abdallah DA, Chedid NF, et al. SARS, MERS and COVID-19: clinical manifestations and organsystem complications: a mini review. Pathog Dis. 2020;78(4):ftaa033.

11. Zhang H, Penninger JM, Li Y, Zhong N, Slutsky AS. Angiotensin-converting enzyme 2 (ACE2) as a SARS-CoV-2 receptor: molecular mechanisms and potential therapeutic target. Intensive Care Med. 2020:46(4):586-90.

12. Chen Y, Guo Y, Pan Y, Zhao ZJ. Structure analysis of the receptor binding of 2019-nCoV. Biochem Biophys Res Commun. 2020;525(1):135-40.

13. Li F. Structure, function, and evolution of coronavirus spike proteins. Annu Rev Virol. 2016;3(1):237-61.

14. Wan Y, Shang J, Graham R, Baric RS, Li F. Receptor recognition by the novel coronavirus from Wuhan: an analysis based on decade-long structural studies of SARS coronavirus. J Virol. 2020;94(7):e00127-20.

15. Yan R, Zhang Y, Li Y, Xia L, Guo Y, Zhou Q. Structural basis for the recognition of SARS-CoV-2 by full-length human ACE2. Science. 2020; 367(6485):1444-8.

16. Kuba K, Imai Y, Rao S, Gao H, Guo F, Guan B, et al. A crucial role of angiotensin converting enzyme 2 (ACE2) in SARS coronavirus-induced lung injury. Nat Med. 2005;11(8):875-9.

17. Helal MA, Shouman S, Abdelwaly A, Elmehrath AO, Essawy M, Sayed SM et al. Molecular basis of the potential interaction of SARS-CoV-2 spike protein to CD147 in COVID-19 associated-lymphopenia. J Biomol Struct Dyn. 2020:1-11

18. Jeffers SA, Tusell SM, Gillim-Ross L, Hemmila EM, Achenbach JE, Babcock GJ, et al. CD209L (L-SIGN) is a receptor for severe acute respiratory syndrome coronavirus. Proc Natl Acad Sci U S A. 2004;101(44):15748-53.

19. Wang Q, Wu J, Wang H, Gao Y, Liu Q, Mu A, et al. Structural basis for RNA replication by the SARS-CoV-2 polymerase. Cell. 2020;182(2):417-28 e13.

20. Romano M, Ruggiero A, Squeglia F, Maga G, Berisio R. A structural view of SARS-CoV-2 RNA replication machinery: RNA synthesis, proofreading and final capping. Cells. 2020;9(5):1267.

21. Poduri R, Joshi G, Jagadeesh G. Drugs targeting various stages of the SARSCoV-2 life cycle: exploring promising drugs for the treatment of Covid-19. Cell Signal. 2020;74:109721.

22. Schoeman D, Fielding BC. Coronavirus envelope protein: current knowledge. Virol J. 2019;16(1):69.

23. Gordon DE, Hiatt J, Bouhaddou M, Rezelj W, Ulferts S, Braberg H, et al. Comparative host-coronavirus protein interaction networks reveal pan-viral disease mechanisms. Science. 2020;370(6521):eabe9403.

24. Trougakos IP, Stamatelopoulos K, Terpos E, Tsitsilonis OE, Aivalioti E, Paraskevis D, et al. Insights to SARS-CoV-2 life cycle, pathophysiology, and rationalized treatments that target COVID-19 clinical complications. J Biomed Sci. 2021;28(1):9.

25. Qi F, Qian S, Zhang S, Zhang Z. Single cell RNA sequencing of 13 human tissues identify cell types and receptors of human coronaviruses. Biochem Biophys Res Commun. 2020;526(1):135-40.

26. Sungnak W, Huang $N$, Becavin C, Berg M, Queen R, Litvinukova M, et al. SARS-CoV-2 entry factors are highly expressed in nasal epithelial cells together with innate immune genes. Nat Med. 2020;26(5):681-7.

27. Fink SL, Cookson BT. Apoptosis, pyroptosis, and necrosis: mechanistic description of dead and dying eukaryotic cells. Infect Immun. 2005;73(4): 1907-16.

28. Jin $Y$, Yang H, Ji W, Wu W, Chen S, Zhang W, et al. Virology, epidemiology, pathogenesis, and control of COVID-19. Viruses. 2020;12(4):40

29. Ye Q, Wang B, Mao J. The pathogenesis and treatment of the 'cytokine Storm' in COVID-19. J Inf Secur. 2020:80(6):607-13.

30. Weiss SR, Navas-Martin S. Coronavirus pathogenesis and the emerging pathogen severe acute respiratory syndrome coronavirus. Microbiol Mol Biol Rev. 2005;69(4):635-64

31. Nadim MK, Forni LG, Mehta RL, Connor MJ Jr, Liu KD, Ostermann M, et al. COVID-19-associated acute kidney injury: consensus report of the 25th acute disease quality initiative (ADQI) workgroup. Nat Rev Nephrol. 2020; 16(12):765.

32. Arachchillage DRJ, Laffan M. Abnormal coagulation parameters are associated with poor prognosis in patients with novel coronavirus pneumonia. J Thromb Haemost. 2020;18(5):1233-4.

33. Karch CM, Goate AM. Alzheimer's disease risk genes and mechanisms of disease pathogenesis. Biol Psychiatry. 2015;77(1):43-51.

34. Jonsson T, Atwal JK, Steinberg S, Snaedal J, Jonsson PV, Bjornsson S, et al. A mutation in APP protects against Alzheimer's disease and age-related cognitive decline. Nature. 2012;488(7409):96-9.

35. Verghese PB, Castellano JM, Holtzman DM. Apolipoprotein E in Alzheimer's disease and other neurological disorders. Lancet Neurol. 2011;10(3):241-52.

36. Shankar GM, Li S, Mehta TH, Garcia-Munoz A, Shepardson NE, Smith I, et al. Amyloid-beta protein dimers isolated directly from Alzheimer's brains impair synaptic plasticity and memory. Nat Med. 2008;14(8):837-42.

37. Jin M, Shepardson N, Yang T, Chen G, Walsh D, Selkoe DJ. Soluble amyloid beta-protein dimers isolated from Alzheimer cortex directly induce tau hyperphosphorylation and neuritic degeneration. Proc Natl Acad Sci U S A. 2011;108(14):5819-24.

38. Serrano-Pozo A, Frosch MP, Masliah E, Hyman BT. Neuropathological alterations in Alzheimer disease. Cold Spring Harb Perspect Med. 2011;1(1): a006189.

39. Scheltens P, Blennow K, Breteler MM, de Strooper B, Frisoni GB, Salloway S, et al. Alzheimer's disease. Lancet. 2016:388(10043):505-17.

40. Matthews FE, Brayne C, Lowe J, McKeith I, Wharton SB, Ince P. Epidemiological pathology of dementia: attributable-risks at death in the Medical Research Council cognitive function and ageing study. PLoS Med. 2009:6(11):e1000180.

41. Heneka MT, Carson MJ, El Khoury J, Landreth GE, Brosseron F, Feinstein DL, et al. Neuroinflammation in Alzheimer's disease. Lancet Neurol. 2015;14(4): 388-405.

42. Guerreiro R, Wojtas A, Bras J, Carrasquillo M, Rogaeva E, Majounie E, et al. TREM2 variants in Alzheimer's disease. N Engl J Med. 2013;368(2):117-27.

43. Griciuc A, Serrano-Pozo A, Parrado AR, Lesinski AN, Asselin CN, Mullin K, et al. Alzheimer's disease risk gene CD33 inhibits microglial uptake of amyloid beta. Neuron. 2013;78(4):631-43.

44. Gao G, Zhao S, Xia X, Li C, Li C, Ji C, et al. Glutaminase C regulates microglial activation and pro-inflammatory exosome release: relevance to the pathogenesis of Alzheimer's disease. Front Cell Neurosci. 2019; $13: 264$.

45. Sheedy FJ, Grebe A, Rayner KJ, Kalantari P, Ramkhelawon B, Carpenter SB, et al. CD36 coordinates NLRP3 inflammasome activation by facilitating intracellular nucleation of soluble ligands into particulate ligands in sterile inflammation. Nat Immunol. 2013;14(8):812-20.

46. Olabarria M, Noristani HN, Verkhratsky A, Rodriguez JJ. Concomitant astroglia atrophy and astrogliosis in a triple transgenic animal model of Alzheimer's disease. Glia. 2010:58(7):831-8.

47. Hawkes CA, McLaurin J. Selective targeting of perivascular macrophages for clearance of beta-amyloid in cerebral amyloid angiopathy. Proc Natl Acad Sci U S A. 2009;106(4):1261-6. 
48. Readhead B, Haure-Mirande JV, Funk CC, Richards MA, Shannon P, Haroutunian $V$, et al. Multiscale analysis of independent Alzheimer's cohorts finds disruption of molecular, genetic, and clinical networks by human Herpesvirus. Neuron. 2018:99(1):64-82 e7.

49. Mancuso R, Sicurella M, Agostini S, Marconi P, Clerici M. Herpes simplex virus type 1 and Alzheimer's disease: link and potential impact on treatment. Expert Rev Anti-Infect Ther. 2019;17(9):715-31.

50. Harris SA, Harris EA. Herpes simplex virus type 1 and other pathogens are key causative factors in sporadic Alzheimer's disease. J Alzheimers Dis. 2015; 48(2):319-53.

51. Romeo MA, Gilardini Montani MS, Gaeta A, D'Orazi G, Faggioni A, Cirone M. HHV-6A infection dysregulates autophagy/UPR interplay increasing beta amyloid production and tau phosphorylation in astrocytoma cells as well as in primary neurons, possible molecular mechanisms linking viral infection to Alzheimer's disease. Biochim Biophys Acta Mol basis Dis. 1866;2020(3): 165647.

52. Bortolotti D, Gentili V, Rotola A, Caselli E, Rizzo R. HHV-6A infection induces amyloid-beta expression and activation of microglial cells. Alzheimers Res Ther. 2019;11(1):104.

53. Ball MJ. Limbic predilection in Alzheimer dementia: is reactivated herpesvirus involved? Can J Neurol Sci. 1982;9(3):303-6.

54. Itzhaki RF, Lathe R, Balin BJ, Ball MJ, Bearer EL, Braak H, et al. Microbes and Alzheimer's disease. J Alzheimers Dis. 2016:51(4):979-84.

55. Letenneur L, Peres K, Fleury H, Garrigue I, Barberger-Gateau P, Helmer C, et al. Seropositivity to herpes simplex virus antibodies and risk of Alzheimer's disease: a population-based cohort study. PLoS One. 2008;3(11):e3637.

56. Roos KL. Encephalitis. Handb Clin Neurol. 2014;121:1377-81.

57. Davis LE, Johnson RT. An explanation for the localization of herpes simplex encephalitis? Ann Neurol. 1979;5(1):2-5.

58. Wozniak MA, Mee AP, Itzhaki RF. Herpes simplex virus type 1 DNA is located within Alzheimer's disease amyloid plaques. J Pathol. 2009;217(1):131-8.

59. Armien AG, Hu S, Little MR, Robinson N, Lokensgard JR, Low WC, et al Chronic cortical and subcortical pathology with associated neurological deficits ensuing experimental herpes encephalitis. Brain Pathol. 2010;20(4): 738-50

60. Harris SA, Harris EA. Molecular mechanisms for herpes simplex virus type 1 pathogenesis in Alzheimer's disease. Front Aging Neurosci. 2018;10:48.

61. Devanand DP. Viral hypothesis and antiviral treatment in Alzheimer's disease. Curr Neurol Neurosci Rep. 2018;18(9):55.

62. Sy M, Kitazawa M, Medeiros R, Whitman L, Cheng D, Lane TE, et al. Inflammation induced by infection potentiates tau pathological features in transgenic mice. Am J Pathol. 2011;178(6):2811-22.

63. Martin-Jimenez P, Munoz-Garcia MI, Seoane D, Roca-Rodriguez L, GarciaReyne A, Lalueza A, et al. Cognitive impairment is a common comorbidity in deceased COVID-19 patients: a hospital-based retrospective cohort study. J Alzheimers Dis. 2020;78(4):1367-72.

64. Matias-Guiu JA, Pytel V, Matias-Guiu J. Death rate due to COVID-19 in Alzheimer's disease and frontotemporal dementia. J Alzheimers Dis. 2020; 78(2):537-41.

65. Hwang JM, Kim JH, Park JS, Chang MC, Park D. Neurological diseases as mortality predictive factors for patients with COVID-19: a retrospective cohort study. Neurol Sci. 2020;41(9):2317-24.

66. Hashim MJ, Alsuwaidi AR, Khan G. Population risk factors for COVID-19 mortality in 93 countries. J Epidemiol Glob Health. 2020;10(3):204-8.

67. Trevisan K, Cristina-Pereira R, Silva-Amaral D, Aversi-Ferreira TA. Theories of aging and the prevalence of Alzheimer's disease. Biomed Res Int. 2019;2019: 9171424.

68. Chen Y, Klein SL, Garibaldi BT, Li H, Wu C, Osevala NM, et al. Aging in COVID-19: vulnerability, immunity and intervention. Ageing Res Rev. 2021; 65:101205.

69. Wu JT, Leung K, Bushman M, Kishore N, Niehus R, de Salazar PM, et al. Estimating clinical severity of COVID-19 from the transmission dynamics in Wuhan, China. Nat Med. 2020;26(4):506-10.

70. Onder G, Rezza G, Brusaferro S. Case-fatality rate and characteristics of patients dying in relation to COVID-19 in Italy. JAMA. 2020;323(18):1775-6.

71. Xia X, Jiang Q, McDermott J, Han JJ. Aging and Alzheimer's disease: comparison and associations from molecular to system level. Aging Cell. 2018;17(5):e12802.

72. Rahman MA, Islam K, Rahman S, Alamin M. Neurobiochemical cross-talk between COVID-19 and Alzheimer's disease. Mol Neurobiol. 2021;58(3): 1017-23.
73. Sugg MM, Spaulding TJ, Lane SJ, Runkle JD, Harden SR, Hege A, et al. Mapping community-level determinants of COVID-19 transmission in nursing homes: a multi-scale approach. Sci Total Environ. 2020;752:141946.

74. Kobayashi R, Hayashi H, Kawakatsu S, Morioka D, Aso S, Kimura M, et al. Recognition of the coronavirus disease 2019 pandemic and face mask wearing in patients with Alzheimer's disease: an investigation at a medical Centre for dementia in Japan. Psychogeriatrics. 2020;20(6):923-5.

75. Tsugawa A, Sakurai S, Inagawa Y, Hirose D, Kaneko Y, Ogawa Y, et al. Awareness of the COVID-19 outbreak and resultant depressive tendencies in patients with severe Alzheimer's disease. J Alzheimers Dis. 2020;77(2):539-41.

76. Kuo CL, Pilling LC, Atkins JL, Masoli JAH, Delgado J, Kuchel GA, et al. APOE e4 genotype predicts severe COVID-19 in the UK biobank community cohort. J Gerontol A Biol Sci Med Sci. 2020;75(11):2231-2.

77. Fuior EV, Gafencu AV. Apolipoprotein C1: its pleiotropic effects in lipid metabolism and beyond. Int J Mol Sci. 2019;20(23):5939.

78. Kulminski AM, Loika Y, Culminskaya I, Huang J, Arbeev KG, Bagley O, et al. Independent associations of TOMM40 and APOE variants with body mass index. Aging Cell. 2019;18(1):e12869.

79. Kulminski AM, Raghavachari N, Arbeev KG, Culminskaya I, Arbeeva L, Wu D, et al. Protective role of the apolipoprotein E2 allele in age-related disease traits and survival: evidence from the long life family study. Biogerontology. 2016;17(5-6):893-905.

80. Green KN, LaFerla FM. Linking calcium to Abeta and Alzheimer's disease. Neuron. 2008;59(2):190-4.

81. Green KN, Peers C. Amyloid beta peptides mediate hypoxic augmentation of ca(2+) channels. J Neurochem. 2001;77(3):953-6.

82. Bezprozvanny I, Mattson MP. Neuronal calcium mishandling and the pathogenesis of Alzheimer's disease. Trends Neurosci. 2008;31(9):454-63.

83. Danta CC. CNS penetration ability: a critical factor for drugs in the treatment of SARS-CoV-2 brain infection. ACS Chem Neurosci. 2020;11(15):2137-44.

84. Chen X, Cao R, Zhong W. Host calcium channels and pumps in viral infections. Cells. 2019;9(1):94

85. Lim KH, Yang S, Kim SH, Joo JY. Elevation of ACE2 as a SARS-CoV-2 entry receptor gene expression in Alzheimer's disease. J Inf Secur. 2020; 81(3):e33-4.

86. Cao Y, Li L, Feng Z, Wan S, Huang P, Sun X, et al. Comparative genetic analysis of the novel coronavirus (2019-nCoV/SARS-CoV-2) receptor ACE2 in different populations. Cell Discov. 2020;6:11.

87. Jiang T, Gao L, Lu J, Zhang YD. ACE2-Ang-(1-7)-mas axis in brain: a potential target for prevention and treatment of ischemic stroke. Curr Neuropharmacol. 2013;11(2):209-17.

88. Rabie MA, Abd El Fattah MA, Nassar NN, El-Abhar HS, Abdallah DM. Angiotensin 1-7 ameliorates 6-hydroxydopamine lesions in hemiparkinsonian rats through activation of MAS receptor/PI3K/Akt/BDNF pathway and inhibition of angiotensin II type-1 receptor/NF-kappaB axis. Biochem Pharmacol. 2018;151:126-34

89. Motaghinejad M, Gholami M. Possible neurological and mental outcomes of COVID-19 infection: a hypothetical role of ACE-2\mas\BDNF signaling pathway. Int J Prev Med. 2020;11:84.

90. Jiang T, Zhang YD, Zhou JS, Zhu XC, Tian YY, Zhao HD, et al. Angiotensin$(1-7)$ is reduced and inversely correlates with tau hyperphosphorylation in animal models of Alzheimer's disease. Mol Neurobiol. 2016;53(4):2489-97.

91. Kehoe PG, Wong S, Al Mulhim N, Palmer LE, Miners JS. Angiotensinconverting enzyme 2 is reduced in Alzheimer's disease in association with increasing amyloid-beta and tau pathology. Alzheimers Res Ther. 2016;8(1):50.

92. Wilcock GK, Esiri MM, Bowen DM, Smith CC. Alzheimer's disease. Correlation of cortical choline acetyltransferase activity with the severity of dementia and histological abnormalities. J Neurol Sci. 1982;57(2-3):407-17.

93. Stanciu GD, Luca A, Rusu RN, Bild V, Beschea Chiriac SI, Solcan C, et al. Alzheimer's disease pharmacotherapy in relation to cholinergic system involvement. Biomolecules. 2019;10(1):40.

94. Chowdhury P, Pathak P. Neuroprotective immunity by essential nutrient "choline" for the prevention of SARS CoV2 infections: an in silico study by molecular dynamics approach. Chem Phys Lett. 2020;761:138057.

95. Cameron B, Landreth GE. Inflammation, microglia, and Alzheimer's disease. Neurobiol Dis. 2010;37(3):503-9.

96. Kim YS, Lee KJ, Kim H. Serum tumour necrosis factor-alpha and interleukin-6 levels in Alzheimer's disease and mild cognitive impairment. Psychogeriatrics. 2017;17(4):224-30. 
97. Chen X, Zhao B, Qu Y, Chen Y, Xiong J, Feng Y, et al. Detectable serum SARS-CoV-2 viral load (RNAaemia) is closely correlated with drastically elevated interleukin 6 (IL-6) level in critically ill COVID-19 patients. Clin Infect Dis. 2020;71(8):1937-42.

98. Wang JH, Wu YJ, Tee BL, Lo RY. Medical comorbidity in Alzheimer's disease: a nested case-control study. J Alzheimers Dis. 2018;63(2):773-81.

99. Zhou Y, Chi J, Lv W, Wang Y. Obesity and diabetes as high-risk factors for severe coronavirus disease 2019 (Covid-19). Diabetes Metab Res Rev. 2021; 37(2):e3377.

100. Zhou F, Yu T, Du R, Fan G, Liu Y, Liu Z, et al. Clinical course and risk factors for mortality of adult inpatients with COVID-19 in Wuhan, China: a retrospective cohort study. Lancet. 2020;395(10229):1054-62.

101. Barron E, Bakhai C, Kar P, Weaver A, Bradley D, Ismail H, et al. Associations of type 1 and type 2 diabetes with COVID-19-related mortality in England: a whole-population study. Lancet Diabetes Endocrinol. 2020;8(10):813-22.

102. Lim S, Bae JH, Kwon HS, Nauck MA. COVID-19 and diabetes mellitus: from pathophysiology to clinical management. Nat Rev Endocrinol. 2021;17(1): $11-30$.

103. Wolf-Klein GP, Siverstone FA, Brod MS, Levy A, Foley CJ, Termotto V, et al. Are Alzheimer patients healthier? J Am Geriatr Soc. 1988;36(3):219-24.

104. Thancharoen O, Limwattananon C, Waleekhachonloet O, Rattanachotphanit T, Limwattananon P, Limpawattana P. Ginkgo biloba extract (EGb761), cholinesterase inhibitors, and memantine for the treatment of mild-tomoderate Alzheimer's disease: a network meta-analysis. Drugs Aging. 2019; 36(5):435-52.

105. Caraci F, Sultana J, Drago F, Spina E. Clinically relevant drug interactions with anti-Alzheimer's drugs. CNS Neurol Disord Drug Targets. 2017;16(4): 501-13.

106. Balli N, Kara E, Demirkan K. The another side of COVID-19 in Alzheimer's disease patients: drug-drug interactions. Int J Clin Pract. 2020;74(10):e13596.

107. Yeh RF, Gaver VE, Patterson KB, Rezk NL, Baxter-Meheux F, Blake MJ, et al. Lopinavir/ritonavir induces the hepatic activity of cytochrome P450 enzymes CYP2C9, CYP2C19, and CYP1A2 but inhibits the hepatic and intestinal activity of CYP3A as measured by a phenotyping drug cocktail in healthy volunteers. J Acquir Immune Defic Syndr. 2006;42(1):52-60.

108. Tombini M, Sicari M, Pellegrino G, Ursini F, Insarda P, Di Lazzaro V. Nutritional status of patients with Alzheimer's disease and their caregivers. J Alzheimers Dis. 2016;54(4):1619-27.

109. Li T, Zhang Y, Gong C, Wang J, Liu B, Shi L, et al. Prevalence of malnutrition and analysis of related factors in elderly patients with COVID-19 in Wuhan, China. Eur J Clin Nutr. 2020;74(6):871-5.

110. Hudson L, Chittams J, Griffith C, Compher C. Malnutrition identified by academy of nutrition and dietetics/American society for parenteral and enteral nutrition is associated with more 30-day readmissions, greater hospital mortality, and longer hospital stays: a retrospective analysis of nutrition assessment data in a major medical center. JPEN J Parenter Enteral Nutr. 2018;42(5):892-7

111. Fedele D, De Francesco A, Riso S, Collo A. Obesity, malnutrition, and trace element deficiency in the coronavirus disease (COVID-19) pandemic: an overview. Nutrition. 2021:81:111016.

112. Varatharaj A, Thomas N, Ellul MA, Davies NWS, Pollak TA, Tenorio EL, et al. Neurological and neuropsychiatric complications of COVID-19 in 153 patients: a UK-wide surveillance study. Lancet Psychiatry. 2020;7(10): 875-82.

113. Helms J, Kremer S, Merdji H, Clere-Jehl R, Schenck M, Kummerlen C, et al. Neurologic features in severe SARS-CoV-2 infection. N Engl J Med. 2020; 382(23):2268-70.

114. Mikkelsen ME, Christie JD, Lanken PN, Biester RC, Thompson BT, Bellamy SL, et al. The adult respiratory distress syndrome cognitive outcomes study: long-term neuropsychological function in survivors of acute lung injury. Am J Respir Crit Care Med. 2012;185(12):1307-15.

115. Song E, Zhang C, Israelow B, Lu-Culligan A, Prado AV, Skriabine S, et al. Neuroinvasion of SARS-CoV-2 in human and mouse brain. J Exp Med. 2021; 218(3):e20202135.

116. Matschke J, Lutgehetmann M, Hagel C, Sperhake JP, Schroder AS, Edler C, et al. Neuropathology of patients with COVID-19 in Germany: a postmortem case series. Lancet Neurol. 2020;19(11):919-29.

117. Baig AM, Khaleeq A, Ali U, Syeda H. Evidence of the COVID-19 virus targeting the CNS: tissue distribution, host-virus interaction, and proposed neurotropic mechanisms. ACS Chem Neurosci. 2020;11(7):995-8.
118. Team Cl. Clinical and virologic characteristics of the first 12 patients with coronavirus disease 2019 (COVID-19) in the United States. Nat Med. 2020; 26(6):861-8.

119. Buzhdygan TP, DeOre BJ, Baldwin-Leclair A, Bullock TA, McGary HM, Khan $J A$, et al. The SARS-CoV-2 spike protein alters barrier function in 2D static and 3D microfluidic in-vitro models of the human blood-brain barrier. Neurobiol Dis. 2020;146:105131.

120. Palasca O, Santos A, Stolte C, Gorodkin J, Jensen L. TISSUES 2.0: an integrative web resource on mammalian tissue expression. Database (Oxford). 2018;2018:bay028.

121. Lechien JR, Chiesa-Estomba CM, De Siati DR, Horoi M, Le Bon SD, Rodriguez A, et al. Olfactory and gustatory dysfunctions as a clinical presentation of mild-tomoderate forms of the coronavirus disease (COVID-19): a multicenter European study. Eur Arch Otorhinolaryngol. 2020;277(8):2251-61.

122. Netland J, Meyerholz DK, Moore S, Cassell M, Perlman S. Severe acute respiratory syndrome coronavirus infection causes neuronal death in the absence of encephalitis in mice transgenic for human ACE2. J Virol. 2008; 82(15):7264-75

123. Pavillet CE, Selvakumar TA. SARS-CoV-2 on the neural battleground. Nat Rev Immunol. 2020;20(9):518.

124. Brann DH, Tsukahara T, Weinreb C, Lipovsek M, Van den Berge K, Gong B, et al. Non-neuronal expression of SARS-CoV-2 entry genes in the olfactory system suggests mechanisms underlying COVID-19-associated anosmia. Sci Adv. 2020;6(31):eabc5801.

125. Deffner F, Scharr M, Klingenstein S, Klingenstein M, Milazzo A, Scherer S, et al. Histological evidence for the enteric nervous system and the choroid plexus as alternative routes of Neuroinvasion by SARS-CoV2. Front Neuroanat. 2020;14:596439.

126. Lamers MM, Beumer J, van der Vaart J, Knoops K, Puschhof J, Breugem TI, et al. SARS-CoV-2 productively infects human gut enterocytes. Science. 2020;369(6499):50-4

127. Varga Z, Flammer AJ, Steiger $P$, Haberecker $M$, Andermatt $R$, Zinkernagel AS, et al. Endothelial cell infection and endotheliitis in COVID-19. Lancet. 2020 395(10234):1417-8.

128. Oxley TJ, Mocco J, Majidi S, Kellner CP, Shoirah H, Singh IP, et al. Largevessel stroke as a presenting feature of Covid-19 in the young. N Engl J Med. 2020;382(20):e60

129. Ritchie K, Chan D, Watermeyer T. The cognitive consequences of the COVID-19 epidemic: collateral damage? Brain Commun. 2020;2(2):fcaa069.

130. Jacomy H, Fragoso G, Almazan G, Mushynski WE, Talbot PJ. Human coronavirus OC43 infection induces chronic encephalitis leading to disabilities in BALB/C mice. Virology. 2006;349(2):335-46.

131. Cojocaru IM, Cojocaru M, Miu G, Sapira V. Study of interleukin-6 production in Alzheimer's disease. Rom J Intern Med. 2011;49(1):55-8.

132. Rachal Pugh C, Fleshner M, Watkins LR, Maier SF, Rudy JW. The immune system and memory consolidation: a role for the cytokine IL-1beta. Neurosci Biobehav Rev. 2001;25(1):29-41.

133. Bialuk I, Taranta A, Winnicka MM. IL-6 deficiency alters spatial memory in 4and 24-month-old mice. Neurobiol Learn Mem. 2018;155:21-9.

134. Depino AM, Alonso M, Ferrari C, del Rey A, Anthony D, Besedovsky H, et al. Learning modulation by endogenous hippocampal IL-1: blockade of endogenous IL-1 facilitates memory formation. Hippocampus. 2004;14(4): 526-35.

135. Jones HD, Crother TR, Gonzalez-Villalobos RA, Jupelli M, Chen S, Dagvadorj $J$, et al. The NLRP3 inflammasome is required for the development of hypoxemia in LPS/mechanical ventilation acute lung injury. Am J Respir Cell Mol Biol. 2014;50(2):270-80.

136. Tejera D, Mercan D, Sanchez-Caro JM, Hanan M, Greenberg D, Soreq H, et al. Systemic inflammation impairs microglial Abeta clearance through NLRP3 inflammasome. EMBO J. 2019;38(17):e101064.

137. Overmyer KA, Shishkova E, Miller IJ, Balnis J, Bernstein MN, Peters-Clarke TM, et al. Large-scale multi-omic analysis of COVID-19 severity. Cell Syst. 2021; 12(1):23-40 e7.

138. Yang AC, Kern F, Losada PM, Maat CA, Schmartz G, Fehlmann T, et al. Broad transcriptional dysregulation of brain and choroid plexus cell types with COVID-19. BioRxiv. 2020. https://doi.org/10.1101/2020.10.22.349415.

139. Tang H, Gao Y, Li Z, Miao Y, Huang Z, Liu X, et al. The noncoding and coding transcriptional landscape of the peripheral immune response in patients with COVID-19. Clin Transl Med. 2020;10(6):e200.

140. Jacob F, Pather SR, Huang WK, Zhang F, Wong SZH, Zhou H, et al. Human pluripotent stem cell-derived neural cells and brain organoids reveal SARS- 
CoV-2 neurotropism predominates in choroid plexus epithelium. Cell Stem Cell. 2020;27(6):937-50 e9.

141. Rissman RA, Lee KF, Vale W, Sawchenko PE. Corticotropin-releasing factor receptors differentially regulate stress-induced tau phosphorylation. J Neurosci. 2007;27(24):6552-62.

142. Dong H, Goico B, Martin M, Csernansky CA, Bertchume A, Csernansky JG. Modulation of hippocampal cell proliferation, memory, and amyloid plaque deposition in APPsw (Tg2576) mutant mice by isolation stress. Neuroscience. 2004;127(3):601-9.

143. Perrin R, Riste L, Hann M, Walther A, Mukherjee A, Heald A. Into the looking glass: post-viral syndrome post COVID-19. Med Hypotheses. 2020;144: 110055

144. Chrousos GP, Kaltsas G. Post-SARS sickness syndrome manifestations and endocrinopathy: how, why, and so what? Clin Endocrinol. 2005;63(4):363-5.

145. Moldofsky H, Patcai J. Chronic widespread musculoskeletal pain, fatigue, depression and disordered sleep in chronic post-SARS syndrome; a casecontrolled study. BMC Neurol. 2011;11(1):37.

146. Evans C, Davies P. SARS-CoV-2 paediatric inflammatory syndrome. Paediatr Child Health (Oxford). 2021;31(3):110-5.

147. Chang KH, Lyu RK, Ro YS, Chen YC, Ro LS, Chang HS, et al. Increased serum concentrations of transforming growth factor-beta1 (TGF-beta1) in patients with Guillain-Barre syndrome. Clin Chim Acta. 2016:461:8-13.

148. Zhang X, Huang WJ, Chen WW. TGF-beta1 factor in the cerebrovascular diseases of Alzheimer's disease. Eur Rev Med Pharmacol Sci. 2016;20(24): 5178-85.

149. Justice NJ, Huang L, Tian JB, Cole A, Pruski M, Hunt AJ Jr, et al. Posttraumatic stress disorder-like induction elevates beta-amyloid levels, which directly activates corticotropin-releasing factor neurons to exacerbate stress responses. J Neurosci. 2015;35(6):2612-23.

150. Devi L, Alldred MJ, Ginsberg SD, Ohno M. Sex- and brain region-specific acceleration of beta-amyloidogenesis following behavioral stress in a mouse model of Alzheimer's disease. Mol Brain. 2010;3:34.

151. Papaspyropoulos A, Tsolaki M, Foroglou N, Pantazaki AA. Modeling and targeting Alzheimer's disease with organoids. Front Pharmacol. 2020;11:396.

152. Cagnin A, Di Lorenzo R, Marra C, Bonanni L, Cupidi C, Lagana V, et al. Behavioral and psychological effects of coronavirus disease-19 quarantine in patients with dementia. Front Psychiatry. 2020:11:578015.

153. Padala KP, Parkes CM, Padala PR. Neuropsychological and functional impact of COVID-19 on mild cognitive impairment. Am J Alzheimers Dis Other Dement. 2020;35:1533317520960875.

154. Cohen G, Russo MJ, Campos JA, Allegri RF. COVID-19 epidemic in Argentina: worsening of behavioral symptoms in elderly subjects with dementia living in the community. Front Psychiatry. 2020;11:866.

155. Wang H, Li T, Barbarino P, Gauthier S, Brodaty H, Molinuevo JL, et al. Dementia care during COVID-19. Lancet. 2020;395(10231):1190-1.

156. Stephen R, Hongisto K, Solomon A, Lonnroos E. Physical activity and Alzheimer's disease: a systematic review. J Gerontol A Biol Sci Med Sci. 2017; 72(6):733-9.

157. Norton S, Matthews FE, Barnes DE, Yaffe K, Brayne C. Potential for primary prevention of Alzheimer's disease: an analysis of population-based data. Lancet Neurol. 2014;13(8):788-94.

158. Muller P, Achraf A, Zou L, Apfelbacher C, Erickson Kl, Muller NG. COVID-19, physical (in-)activity, and dementia prevention. Alzheimers Dement (N Y). 2020;6(1):e12091.

Ready to submit your research? Choose BMC and benefit from:

- fast, convenient online submission

- thorough peer review by experienced researchers in your field

- rapid publication on acceptance

- support for research data, including large and complex data types

- gold Open Access which fosters wider collaboration and increased citations

- maximum visibility for your research: over $100 \mathrm{M}$ website views per year

At $\mathrm{BMC}$, research is always in progress.

Learn more biomedcentral.com/submissions 